\section{Palabra plena. Conversaciones con psicoanalistas}

\author{
Editorial Bonaventuriana, Universidad de San \\ Buenaventura Cali
}

Jhonny Javier Orejuela (compilador)

Año: 2012

\section{Número de páginas: 274}

Por: Alejandra Ordóñez R.

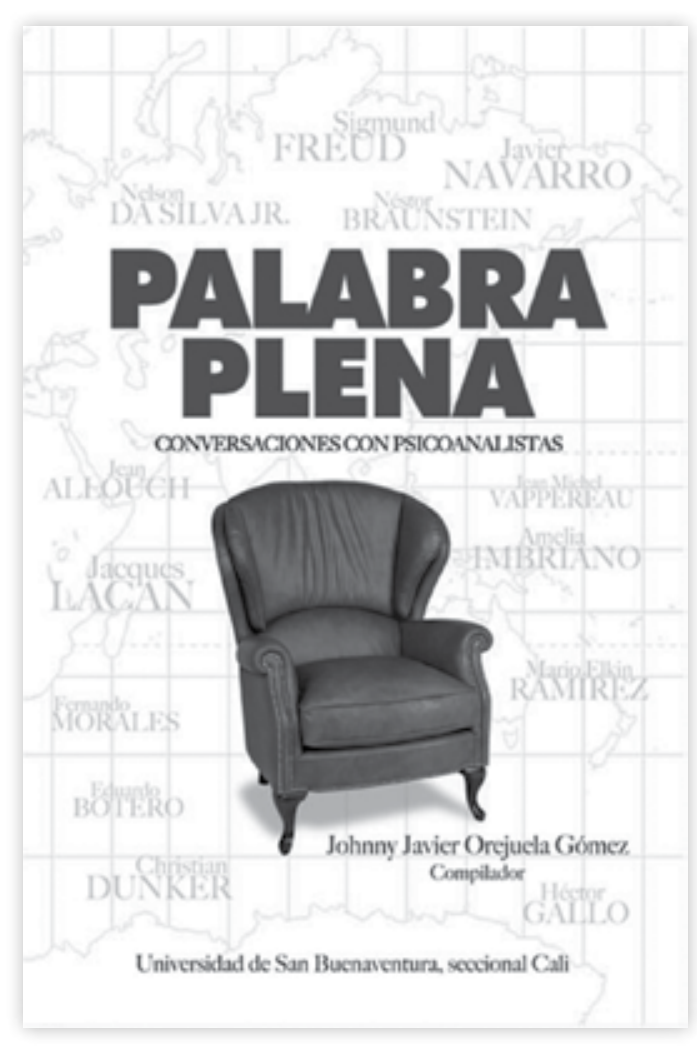

Palabra plena es a grandes rasgos un libro de entrevistas realizadas a diferentes psicoanalistas en momentos y lugares distintos. Diversas nacionalidades y disímiles recorridos académicos y profesionales convergen en este libro que como su título lo sugiere, es un acercamiento al psicoanálisis a través de conversaciones con algunos de sus principales representantes.

Lo anterior haría pensar en la descripción de un texto cuyos creadores se han dedicado escuetamente a la tarea de hacerles entrevistas a psicoanalistas e incluirlas en un mismo producto; sin embargo, este no es el caso de Palabra plena. Se trata de un libro que tiene una historia anudada a un deseo de producir conocimiento, de aportar, de multiplicar las palabras, de movilizar; pero sobre todo, de exponer el psicoanálisis con la misma pasión con la que lo han experimentado los autores en su historia personal.

La riqueza de Palabra plena radica en la intención con la que fue realizado; la intención de sus entrevistadores, de sus entrevistados y el deseo que atravesó su realización, que como lo plantea su compilador Johnny Orejuela, estuvo dirigida a entregar a los estudiantes una producción intelecel profesor Orejuela- que traducida al lenguaje de la conversación y sin dejar de lado el rigor teórico es contada a partir de la historia personal y singular que llevó a cada uno de los entrevistados a enamorarse del psicoanálisis y entrar en transferencia con él.

Leer la entrevista El valor de la vida, una rara entrevista con Freud que le da apertura al libro, es darse cuenta de que detrás del "gran padre del psicoanálisis" subyace el hombre cuyo recorrido como fundador del psicoanálisis no fue ajeno a su propia existencia. Es la prueba de que incluso el más grande de los psicoanalistas permitió que sus rutas interiores convergieran para que de ahí surgiera una práctica clínica que le apuntara a lo singular, al deseo de cada sujeto. Lo que nos deja la conversación con Freud es su intención de someter a análisis su propia historia, una intención clara de transformación, de rectificación subjetiva, que derivó en una posición única frente a la vida misma: "Setenta años me han enseñado tual -el psicoanálisis "puro y duro" del que habla

ALEJANDRA ORDÓÑEZ R. Estudiante de IX semestre de la Facultad de Psicología de la Universidad San Buenaventura Cali. Email: alejandra. ordonezro@hotmail.com 
a aceptar la vida con serena humildad", nos dice para empezar. Detrás del teórico se parapeta el hombre que le dio sentido a su experiencia en la clínica a partir de su propia vida, de la relación con su padre y sus hijos e incluso que transformó su posición en relación con el psicoanálisis y con sus propios hallazgos científicos a partir del análisis de su experiencia de vida, y si se quiere, a partir de su enfermedad: "No permito que ninguna reflexión filosófica arruine mi disfrute de las cosas simples de la vida. [...] La vida cambia, el psicoanálisis también cambia. Está apenas en el comienzo de una nueva ciencia” (p. 47).

Así, encontrar en Palabra plena una reflexión sobre el psicoanálisis pero enriquecida con el discurso propio de una vida de sufrimientos, alegrías, amores, deseos y goce, es ubicarse en un frente teórico distinto: el de las palabras, el del psicoanálisis de los relatos de vida.

En esta misma vía nos encontramos con una entrevista realizada a Lacan: Freud por siempre, en la cual vemos un Lacan hablando al mejor estilo de quien no intenta agradar a nadie. Con la necedad propia de su discurso y la implacable brillantez de sus argumentos, nos cuenta sobre la obra de Freud y sobre sus aportes: "[...] lo que sí es cierto es que nos ha dado a conocer cosas completamente nuevas que ni siquiera habríamos imaginado antes de él [...]" (p. 53). En esta entrevista, Lacan cuenta lo que Freud representó y representará para el psicoanálisis, pero también nos advierte que en relación con la práctica psicoanalítica se debe asumir una postura ética y responsable a la hora de autorizarse como psicoanalista: "[...] proponer a la gente ayudarle significa un éxito asegurado y la clientela se atropella a sus puertas. El psicoanálisis es otra cosa" (p.53).

Abriendo el espectro hacia la compresión de lo real, lo simbólico y lo imaginario, esferas que configuran la estructura psíquica de un sujeto, Lacan expone de manera accesible lo más complejo de su obra, citando ejemplos de lo que angustia a un ser humano y la forma como el psicoanálisis, a partir de la relación sujeto-analista, encuentra la manera de tratar el padecimiento psíquico.

Por otro lado, el libro nos ofrece a quienes como estudiantes hemos encontrado en el psicoanálisis una perspectiva de formación académica, intelec- tual y de práctica profesional, la valiosa experiencia de psicoanalistas de larga trayectoria así como de intelectuales de la talla del doctor Néstor Braunstein, quien ubica al psicoanálisis en el discurso contemporáneo. El doctor Braunstein nos habla de su experiencia personal, de la forma como llegó al psicoanálisis y nos invita a pensar en él a partir de una postura política e histórica y a cuestionarnos acerca de la formación académica y de la práctica profesional de las nuevas generaciones de psicoanalistas. Asimismo, deja abierta la invitación a estudiantes y docentes interesados por el psicoanálisis a movilizarse en esta vía no sin antes advertir sobre el riesgo que implica subvertir el orden y el poder institucional y los alcances que conlleva el hecho de asumir una postura crítica para hacerle frente a nuestra realidad actual, a lo cual añade el relato de su propia experiencia como docente: "Valga decir que nuestra enseñanza es una maldición que nos ha seguido durante bastante tiempo; yo diría que es una constante. En la medida en que nuestra enseñanza tiene éxito se transforma en un peligro a evitar" (p, 81).

Por su parte, Jean Allouch psicoanalista francés, nos introduce en el debate acerca del lugar del psicoanálisis en la universidad. Su posición es contraria a su aprendizaje en el contexto universitario de América Latina. Sin embargo, lejos de sorprendernos o desanimarnos como estudiantes "inquietos" (según su propia expresión) nos incita a tomarlo como un desafío, como una exhortación en la vía de lo que propone Braunstein: subvertir el orden que ha establecido que el camino "ideal" de un acercamiento al psicoanálisis es el paso por el diván, la experiencia personal por el dispositivo analítico.

Como estudiantes no cuestionamos el hecho de que un psicoanalista se forme en el diván y se autorice a sí mismo después de someter a análisis su propia historia, pero tampoco nos negaremos a la posibilidad de crear, de inquietar y de movilizar nuestro propio recorrido desde la universidad, ni de someter a discusión al psicoanálisis con otras disciplinas de las ciencias sociales; y por qué no, de construir con base en nuestra propia experiencia un camino motivado por el deseo de conocer sobre psicoanálisis. Solo así será posible pensar un psicoanálisis menos dogmático, un psicoanálisis en extensión. Se trata de poner en práctica aquello a lo que nos invita Braunstein: "[...] debe defenderse 
la idea de que la universidad sea un espacio donde todos los discursos tengan cabida, como un esporo, el único foro posible dentro de un mundo donde todas las instituciones están limitadas" (p. 75).

De otro lado, nos encontramos con cuestiones que nos conciernen como estudiantes y profesionales de una ciencia social inscrita dentro de una época histórica con características y problemáticas particulares. Palabra plena nos brinda la posibilidad de hacer una reflexión propia a partir de la comprensión de lo que los entrevistados nos proponen, el amor Lacan que propone Allouch y su reflexión "el psicoanálisis será foucaultiano o no será más”. Por su parte Amelia Imbriano nos introduce en el mundo de la psicosis, que rara vez se incluye en nuestra formación académica. Nos cuenta sobre la dirección de la cura en la psicosis y la intervención clínica que aun se recomienda retomando la teorización de Lacan y su planteamiento de la clínica de lo real, de la clínica del goce. Con una de las expresiones más llamativas de su entrevista nos reafirma su postura en relación con el psicoanálisis y la universidad: “'Señor, llegó tarde a ese debate! Le guste o no le guste a usted, el psicoanálisis está en la universidad” (p. 109).

Durante su entrevista, Jean Michel cuenta el efecto que produjo el texto de Freud Más allá del principio del placer, el cual jugó un papel importante en la llegada de Vappereau al psicoanálisis. Cuenta sobre su historia personal como analizante y analista y la influencia de Freud y Lacan en su propia construcción teórica. Sin embargo, esta entrevista nos ofrece una perspectiva distinta del psicoanálisis. Por un lado, nos introduce en la reflexión de la clínica psicoanalítica y de la clínica médica, y por otro lado nos encontramos con una propuesta de psicoanálisis abierto a otras disciplinas como la matemática, la física y la topología, lo cual implica un reto para las nuevas generaciones de psicoanalistas. Se trata de una propuesta en la vía de lo que propone Alberto Valencia en el prólogo del libro Abrir el psicoanálisis.

Las entrevistas a Christian Dunker y a Nelson Da silva Jr., psicoanalistas brasileros, nos enfrentan a un desafío como lectores, como estudiantes y como profesionales. Es un texto que nos exige leer en otro idioma, pero además nos exhorta a comprender otros asuntos del psicoanálisis. Nos insta a tener en cuenta lo que se construye a partir del psicoanálisis en otros países de Latinoamérica y por tanto nos ubica frente al "plus" de Palabra plena del cual habla el compilador. Así, Palabra plena es una aproximación (guardando las proporciones) a un estado del arte de la cuestión psicoanalítica y por tanto es un aporte valioso a nuestra formación.

Las entrevistas nos acercan a casos con los cuales nos podríamos sentir identificados como estudiantes de psicología. Hablan de su recorrido como psicoanalistas, de su experiencia personal (una "experiencia singular", como lo nombra Javier Navarro) y cómo se interesaron por primera vez en esta disciplina. Sin embargo, introducen una discusión importante que nos atańe como futuros profesionales interesados en el psicoanálisis y en las ciencias sociales en general: el psicoanálisis aplicado a nuestros contextos, la posibilidad de una perspectiva psicoanalítica dentro de las instituciones y un psicoanálisis capaz de explicar las problemáticas actuales.

Es tomarnos las palabras de Javier Navarro: "No es una teoría acabada, es una teoría en constante formación y una teoría que piensa que es una teoría histórica” (p. 183). Es tener la posibilidad de elaborar una práctica profesional que haga aportes valiosos a la transformación de la sociedad pero sin perder de vista la ética desde la cual se configura el psicoanálisis. Las entrevistas con los psicoanalistas colombianos nos hablan de un psicoanálisis riguroso en su teoría y en su aplicación que nos devuelve la esperanza de un psicoanálisis por fuera del diván, de que sí existe una forma de llevarlo a lo social sin que en el camino se pierda su rigurosidad.

Finalmente, cabe decir que el libro es la posibilidad de leer, de comprender, de tomar distancia y de discutir con base en el psicoanálisis y en nuestra propia formación y experiencia. Es abrir el diálogo hacia un psicoanálisis que dé a la palabra a los estudiantes y a la universidad en general; es una forma de construir un discurso propio, propositivo, de argumentar y deconstruir para construir lo propio; una academia que se sirva del arsenal teórico psicoanalítico para responder a las demandas actuales y específicas de nuestros contextos.

Palabra plena es otra ruta para la transmisión del psicoanálisis que de manera irreverente nos enfrenta a un diálogo casi íntimo con sus representantes. Es otro desafío como estudiantes apasionados y 
movidos por el deseo de ser analistas o de hacer a partir del psicoanálisis. Para mí es coquetear de manera certera con el deseo de análisis y qué mejor forma de hacerlo que como lo propone Lacan: "En el psicoanálisis no hay solución inmediata, solo la larga y paciente investigación de las razones" (p. 55) y el texto es otra forma de investigar esas razones. Total, como diría el mismo Lacan: "La palabra es la gran fuerza del psicoanálisis [...] y toda palabra amerita una respuesta [...]” (p. 55).

$192<$ Universidad de San Buenaventura, Cali - Colombia 